\title{
Smoking Cessation: An Integral Part of Lung Cancer Treatment
}

\author{
Janine K. Cataldo Sarita Dubey Jodi J. Prochaska \\ Department of Physiological Nursing - Gerontology, University of California San Francisco, San Francisco, Calif., USA
}

\section{Key Words}

Lung cancer $\cdot$ Tobacco dependence $\cdot$ Older smokers

\begin{abstract}
Lung cancer is the leading cause of cancer death in the US. About $50 \%$ of lung cancer patients are current smokers at the time of diagnosis and up to $83 \%$ continue to smoke after diagnosis. A recent study suggests that people who continue to smoke after a diagnosis of early-stage lung cancer almost double their risk of dying. Despite a growing body of evidence that continued smoking by patients after a lung cancer diagnosis is linked with less effective treatment and a poorer prognosis, the belief prevails that treating tobacco dependence is useless. With improved cancer treatments and survival rates, smoking cessation among lung cancer patients has become increasingly important. There is a pressing need to clarify the role of smoking cessation in the care of lung cancer patients. Objective: This paper will report on the benefits of smoking cessation for lung cancer patients and the elements of smoking cessation treatment, with consideration of tailoring to the needs of lung cancer patients. Results: Given the significant benefits of smoking cessation and that tobacco dependence remains a challenge for many lung cancer patients, cancer care providers need to offer full support and intensive treatment with a smoking cessation program that is tailored to lung cancer patients' specific needs. Conclusion: A tobacco dependence treatment plan for lung cancer patients is provided.
\end{abstract}

Copyright ๑ 2010 S. Karger AG, Basel

\section{Smoking Cessation: An Integral Part of Lung Cancer Treatment}

Lung cancer is the leading cause of cancer death in the United States [1]. Two or 3 out of every 100 men and 1 or 2 out of every 100 women, who are now 60 years old, will get lung cancer sometime during the next 10 years [1]. Cigarette smoking is responsible for an estimated $90 \%$ of all lung cancers [2]. The estimates for the prevalence of smoking at the time of lung cancer diagnosis have ranged from 24 to $60 \%$, compared with $12-29 \%$ among the general US population [3-7]. Up to $83 \%$ of all smokers continue to smoke after a diagnosis of lung cancer $[5,8,9]$. Parsons et al. [10] found in a review of 10 studies that people who continue to smoke after a diagnosis of early stage lung cancer almost double their risk of dying. Despite a growing body of evidence that smoking cessation after a lung cancer diagnosis is linked to more effective treatment and a better prognosis, the belief prevails that treating tobacco dependence is useless [11].

Survival rates for lung cancer are improving every year; currently the expected 5-year survival for non-small cell lung cancer (NSCLC) is $60-75 \%$ for stage I and $36-$ $60 \%$ for stage II disease [12]. New anticancer agents, in-

The content is solely the responsibility of the authors and does not represent the official views of the California TRDRP or NIDA. No Human Subject issues are involved, and there is no review board application.

\begin{tabular}{ll}
\hline KARGER & $\odot$ 2010 S. Karger AG, Basel \\
$\begin{array}{l}\text { Fax }+41613061234 \\
\begin{array}{l}\text { E-Mail karger@karger.ch } \\
\text { www.karger.com }\end{array}\end{array}$ & $\begin{array}{l}\text { Accessible online at: } \\
\text { www.karger.com/ocl }\end{array}$
\end{tabular}

Assist. Prof. Janine K. Cataldo, RN, PhD

Department of Physiological Nursing - Gerontology

University of California San Francisco

2 Koret Way, N611, San Francisco, CA 94143-0610 (USA)

Tel. +1 415476 4721, Fax +1 415476 8899, E-Mail janine.cataldo@ nursing.ucsf.edu 
cluding angiogenesis and epidermal growth factor receptor inhibitors, have the potential to increase the number of lung cancer survivors [13]. As lung cancer patients experience longer survival times they are more likely to benefit from the quality of life (QOL) improvements that abstinence from smoking can provide [14, 15]. In the past, smoking cessation has not been considered an integral part of the treatment of cancer but, with improved cancer treatments and survival rates, smoking cessation among cancer patients has become increasingly important [16]. There is a pressing need to clarify the role of smoking cessation in the care of lung cancer patients. This paper will report on the benefits of smoking cessation for lung cancer patients and the elements of effective smoking cessation treatment, with consideration of tailoring to the needs of lung cancer patients.

\section{Benefits of Smoking Cessation for Lung Cancer Patients}

Smoking cessation programs for lung cancer patients have long been thought to have more cost than benefit. Slatore et al. [15] developed a decision analysis model to evaluate the cost effectiveness of a smoking cessation intervention initiated immediately before surgical lung resection. The smoking cessation program was found to be cost-effective at both 1 and 5 years postsurgery. Smoking cessation for lung cancer patients yields both immediate and long-term benefits. There are significant positive effects of smoking cessation on the health of lung cancer patients: decreased risk of disease, increased survival time, decreased postoperative complications, increased efficacy of chemotherapy, decreased radiation therapy complications, and improved QOL.

\section{Immediate Benefits}

The immediate benefits of cessation include improved oxygenation, lowered blood pressure, improved smell, taste, circulation and breathing, increased energy, and improved immune response [17]. Smoking cessation is associated with improved cognitive function, psychological well-being, and self-esteem $[18,19]$. Lung cancer patients report after successful smoking cessation all of the same benefits plus decreased fatigue and shortness of breath, increased activity level, and improved performance status, appetite, sleep, and mood $[18,20,21]$. These benefits are of special import because patients with lung cancer have a greater symptom burden than patients with other cancers [22].

\section{Long-Term Benefits}

Decreased Risk of Disease

Patients with pulmonary neoplasms have an increased risk of developing a second tumor of the lung, either at the same time or at a later time. The second tumor can represent an independent primary or a recurrence/metastasis [23]. Smoking cessation can decrease the risk of synchronous multiple primary lung cancer tumors [24], metachronous lung cancers in small cell lung cancer survivors [25], and second primary tumors [25-29].

Nicotine induces polycyclic aromatic hydrocarbons (PAHs), products of incomplete combustion, which are some of the major lung carcinogens found in tobacco smoke [30]. PAHs are also potent inducers of hepatic enzymes [31]. Many drugs are substrates for hepatic CYP1A2, and their metabolism can be induced in smokers, resulting in a clinically significant decrease in pharmacologic effects. Thus, smokers may require higher doses of drugs that are CYP1A2 substrates. It is important to recognize that these pharmacokinetic drug interactions are caused by the PAHs in tobacco smoke, not the nicotine. Pharmacodynamic drug interactions with tobacco smoke are largely due to nicotine. Because it activates the sympathetic nervous system, nicotine can counter the pharmacologic actions of certain drugs [32]. Nicotine replacement therapy does not contribute to the pharmacokinetic drug interactions discussed in this article [32].

Nicotine itself is not carcinogenic, but it has been shown that, in vivo, nicotine can induce the proliferation of lung cancer cell lines, promote angiogenesis, and promote resistance to apoptosis (cell death) induced by chemotherapeutic agents [33]. These events are mediated through the nicotinic acetylcholine receptors (nAChRs) on lung cancer cells which impact on the efficacy of cisplatin, a frequently used chemotherapeutic agent [33]. Nicotine can contribute to the progression of lung cancers because nicotine can promote anchorage-independent growth in NSCLCs and induce morphological changes characteristic of a migratory, invasive phenotype in NSCLCs [34].

Tucker [25] found that, compared to the general population, the risk of all second cancers among NSCLC patients was increased 3.5 times. Among those who received chest irradiation, second lung cancer risk was increased 13-fold in comparison to a 7-fold increase among nonirradiated patients. The risk was highest among current smokers; an interaction was present between chest irradiation and continued smoking $(\mathrm{RR}=21)$, and a 19-fold risk increase was found among current smokers treated with alkylating agents. A synergism between chest radia- 
tion therapy and smoking in the development of second lung cancers was also found [25].

Gritz et al. [35] studied smoking behavior in 840 adults with stage I NSCLC; at the time of diagnosis, $60 \%$ of the patients were smokers. Two years after diagnosis, $40 \%$ of the smokers had quit smoking. According to this study, smoking cessation at the time of diagnosis of lung cancer may reduce the rate of development of metachronous tumors. Richardson et al. [26] found that the relative risk of developing a second lung cancer following curative-intent therapy for squamous cell lung cancer was lower for those who had stopped smoking.

\section{Increased Survival Time}

Smoking cessation after a diagnosis of lung cancer has been linked to increased survival time $[36,37]$. In a review of smoking cessation after diagnosis of a primary lung tumor, Parsons et al. [10] showed that the associated increase in risk of continuing to smoke is modest at around 20\%; the adjusted estimates, however, suggested a more than doubling of the risk of death from continued smoking. Fox et al. [7] found that, among NSCLC patients diagnosed with early-stage disease, current smokers had a poorer prognosis for survival after radiation therapy. In their sample of 237 patients treated with definitive radiation or chemoradiation, 2-year overall survival was calculated from the time of initiation of treatment. Among those with stage I/II disease, current smokers had a 2 -year survival rate of $41 \%$ and a median survival of 13.7 months while nonsmokers had a 2 -year survival rate of $56 \%$ and a median survival of 27.9 months $(p=0.01)$. In a study of 5,229 patients with NSCLC and squamous cell lung cancer, the median survival times among those who had never smoked, former smokers, and current smokers with NSCLC were $1.4,1.3$, and 1.1 years, respectively $(\mathrm{p}<0.01)$. The relative risk per 10 years of smoking abstinence was 0.85 , demonstrating a direct biological effect of smoking on survival [38].

In a 2003 retrospective review (covering a 10-year period) of studies using a concurrent chemoradiotherapy regimen for patients with limited small cell lung cancer, those who continued to smoke during chemoradiotherapy had poorer survival rates than those who did not [39]. Tammemagi et al. [40] found that current smoking at diagnosis was an important independent predictor of shortened lung cancer survival after adjusting for the baseline covariates age, gender, illicit drug use, adverse symptoms, histology, and stage. The relative risk for smoking (current vs. former/never) was 1.37 (95\% CI 1.18-1.59; p < $0.001)$.

Smoking Cessation and Lung Cancer Treatment
In 2010, Parsons et al. [10] conducted a systematic review with meta-analysis on evidence that smoking cessation after diagnosis of a primary lung tumor affects prognosis. The review revealed evidence that smoking cessation after diagnosis of early-stage lung cancer improves prognostic outcomes and most of the gain is likely due to reduced cancer progression.

Decreased Postoperative Complications

Nonsmokers are at decreased risk of postoperative complications compared with smokers [41]. Yildizeli et al. [42] assessed operative morbidity and mortality on NSCLC patients that underwent a sleeve lobotomy. Current smoking had a significant effect on the development of postoperative complications including infection, bronchopleural fistula [42], and morbidity and mortality [43].

In a 2005 prospective study of patients with primary or secondary lung cancer who were undergoing anatomical lung resection, the 4 groups studied were: nonsmokers (21\%), past quitters of $>2$ months' duration (62\%), recent quitters of $<2$ months' duration (13\%), and ongoing smokers (4\%). Overall pulmonary complications occurred in $8,19,23$, and $23 \%$ of patients in these groups, respectively, with a significant difference between nonsmokers and all smokers $(\mathrm{p}<0.03)[44]$. The risk of pneumonia was significantly lower in nonsmokers (3\%) compared to all smokers (average 11\%; $p<0.05$ ), with no difference detected among subgroups of smokers $(p<0.17)$. When comparing recent quitters with ongoing smokers, no differences in pulmonary complications of pneumonia were found $(\mathrm{p}<0.67)$. A smoking history of $>60$ pack-years (OR 2.54; 95\% CI 1.28-5.04; p < 0.0008) was independently associated with overall pulmonary complications. In patients undergoing thoracotomy for primary lung cancer or metastatic cancer to the lung, there was no evidence of an increase in pulmonary complications among those who quit smoking within 2 months of having undergone surgery [44].

Improved Response to Chemotherapy and Radiation

Both chemotherapy and radiation treatment are likely to produce fewer complications and less morbidity among nonsmokers than smokers [5, 45]. Smoking can have detrimental effects on the efficacy of chemotherapy including chemoresistance, chemoinsensitivity, and altered chemotherapeutic levels [5]. Smoking can significantly affect the pharmacokinetics and toxicity profile of some drugs (e.g. irinotecan) [46]. NSCLC patients with constitutional symptoms (i.e. fever, anorexia, and weight 
loss) and more pack-years of smoking are less likely to respond to chemotherapy [47].

As previously mentioned, some elements of cigarette smoke are known to affect drug metabolizing CYP enzymes and therefore affect treatment outcome. Nicotine in tobacco smoke can decrease the efficacy of certain drugs because of an increase in the metabolism of the drugs through the induction of hepatic enzymes [31]. Van der Bol et al. [46] found that smoking significantly lowers both the exposure to irinotecan and treatmentinduced neutropenia, indicating a potential risk of treatment failure. Shepherd et al. [48] found that twice the normal dose of erlotinib was required to produce the necessary circulating levels of the drug in smokers compared to never-smokers. In a survival analysis, treatment with erlotinib $(\mathrm{p}<0.001)$ and never having smoked $(p<0.01)$ were associated with longer progression-free survival. The interaction between smoking status and treatment was significantly predictive of a differential effect on survival [49]. Studies have suggested that exposure to nicotine might negatively impact on the apoptotic potential of chemotherapeutic agents, including cisplatin [33].

Lung cancer patients who smoke have a $20 \%$ greater chance of experiencing radiation pneumonitis [50]. The number of packages per year of cigarette smoking is significantly positively associated with infection in patients with NSCLC during radiotherapy [51]. Fox et al. [7] found that, among NSCLC patients diagnosed with early stage disease, current smokers had a poorer prognosis for survival after radiation therapy.

\section{Improved QOL}

The cessation of smoking after a lung cancer diagnosis has been consistently linked to an increase in QOL $[7,20$, 26-29, 52]. Garces et al. [20] found that persistent cigarette smoking after a lung cancer diagnosis negatively impacted QOL scores. The adjusted mean total Lung Cancer Symptom Scale (LCSS) scores for never-smokers and persistent smokers were 17.6 and 28.7, respectively ( $\mathrm{p}<$ 0.0001 ), with higher scores indicating greater severity of symptoms. Myrdal et al. [53] found that patients who smoked after surgery experienced impaired QOL compared with nonsmokers, and they had significantly lower scores for mental health and vitality than former smokers who stopped smoking at the time of surgery or before and than those who had never smoked.

Performance status is an important factor in QOL. In a recent study, records were reviewed for 206 patients with NSCLC; those who quit smoking after the diagnosis maintained a better performance status at 6 and 12 months, regardless of disease stage, age, race, sex, therapy types, and comorbidities, than those who continued to smoke. Those who quit smoking maintained a better performance status at 0-6 months (OR 7.09; 95\% CI 1.9925.3 ) and at $0-12$ months (OR 6.99; 95\% CI 1.76-27.7) than those who continued smoking [21].

Although the benefits of cessation are extensive, they are not generally known to lung cancer patients and their clinicians. The specific benefits of smoking cessation (both immediate and long-term) that relate to lung cancer symptom distress need to be incorporated into smoking cessation interventions. Tobacco dependence should be treated at the time of diagnosis of lung cancer, during treatment, and posttreatment.

\section{Tobacco Dependence Treatment}

Given the critical negative health effects of smoking on lung cancer survival and the major health benefits of smoking cessation, it is important that cancer care providers adopt the role of tobacco cessation treatment providers. The following section presents the clinical practice guidelines for treating tobacco dependence with a specific focus on the cancer care providers' role.

Current guidelines for treatment of tobacco dependence have been published by the US Public Health Service in 2000 and updated in 2008 [54]. The guidelines recommend use of the ' 5 A's': clinicians should ask all patients about tobacco use, advise smokers to quit, assess willingness to make a quitting attempt, assist patients with quitting smoking, and arrange follow-up (table 1).

\section{Pharmacotherapy}

In addition to counseling, all smokers attempting cessation should receive pharmacotherapy [55]. First-line, FDA-approved medications for smoking cessation include nicotine replacement therapies (NRT), bupropion sustained release (SR), and varenicline (Chantix) (table 2). An excellent resource that provides accurate, upto-date pharmacotherapy information for smoking cessation treatment, including dosing, precautions, side effects, and costs is: ' $\mathrm{Rx}$ for Change', sponsored by the University of California, San Francisco School of Pharmacy (http://rxforchange.ucsf.edu). Rx for Change for Cancer Care Providers is a brief curriculum designed specifically for treating tobacco dependence in cancer patients and survivors. 
Table 1. The five A's of tobacco dependence treatment adapted for lung cancer patients

Ask. The most important first step to treating tobacco dependence is identifying tobacco users. Clinicians may be reluctant to ask lung cancer patients if they smoke; this may be due to misinformation about the benefits of treatment or as a result of an underlying belief that it is 'too late' [11]. Ask every patient at every contact if they smoke tobacco.

Assessment. The primary goal of assessment is to determine the patient's readiness to quit, which will inform the type of assistance provided in the next step. Readiness to quit smoking has been conceptualized as a series of stages from precontemplation (no immediate intention to stop smoking) to contemplation (intending to quit in the next 6 months), preparation (considering quitting in the next month), action (quitting smoking for less than 6 months), and maintenance (smoke-free for at least 6 months) [92].

Advise. All smokers should be advised to quit smoking. The advice should be clear, strong, and compassionate. Ideally, link the advice to the patient's individual clinical situation. For example, 'Quitting smoking is critical to maximizing your recovery from surgery, your chemotherapy efficacy, and your long-term survival' [54].

Assist. If the patient is unwilling to make a quitting attempt (precontemplation or contemplation), the clinician should provide education and a motivational intervention to increase the perceived benefits of quitting smoking, help to address barriers to quitting (e.g. concerns about nicotine withdrawal, stress), and arrange to address tobacco dependence at the next visit to the clinic. If the patient is ready to quit in the next 30 days (preparation stage), behavioral strategies should be emphasized with a set quitting date, a quitting plan developed, and cessation pharmacotherapy prescribed, as appropriate. A patient in action, who recently quit within the last 6 months, will need continued support and encouragement and reminders regarding the need to abstain from all tobacco use - not even a puff. A patient in maintenance, who has been off of tobacco for more than 6 months, is usually stable but often needs to be reminded to remain vigilant for potential triggers for relapse [54].

Arrange. Research indicates a dose response relationship between increased patient success with quitting smoking and increased clinical contacts [54]. Further, attention to tobacco use by more clinical team members increases the likelihood of patients successfully quitting smoking. Any clinician can initiate the quitting process by asking and advising and then assisting with cessation and arranging follow-up or referring the patient to additional resources (e.g. quit smoking groups, toll-free quit lines).

- Nicotine Replacement Therapy. NRT is based on the principle that nicotine is the dependence-producing constituent of cigarette smoking and that smoking cessation can be achieved by replacing nicotine without the toxins in cigarette smoke [56]. The goal is to relieve the symptoms of withdrawal, which allows the patient to focus on conditioning factors when attempting to stop smoking. NRT products are currently available over the counter and are the first-line medication choice of many smokers attempting to quit on their own. Because NRT has been deemed safe and effective and major side effects are very rare, they should be recommended to all smokers including cancer patients, except for those few for whom they are medically contraindicated. These include patients with underlying cardiovascular disease: recent myocardial infarctions, life-threatening arrhythmias, and severe angina. NRT is not recommended for smokeless tobacco users or individuals smoking fewer than 10 cigarettes per day [54]. Patient education and follow-up is important for successful cessation. Dose tapering is not required when discontinuing treatment.

- Bupropion (SR). Bupropion SR is a norepinephrine and dopamine re-uptake blocker and is also commonly used as an antidepressant. Its clinical effects are a decreased craving for cigarettes and symptoms of nicotine withdrawal [54]. Clinical trials have demonstrated bupropion's efficacy as a smoking cessation adjunct in populations of individuals who have a history of major depressive disorder, as well as those who do not [57]. Bupropion SR can be safely used with NRT. However, it should be avoided in patients with an increased risk for seizures. The possibility of age-related slower drug clearance mandates a modification of the standard bupropion dosing protocol: $150 \mathrm{mg} /$ day for the first week; if no adverse effects occur, increase to 300 $\mathrm{mg}$ for the second week; if no adverse effects occur, maintain this dosage for 12 weeks [58].

- Varenicline (Chantix). Varenicline is a partial nicotinic agonist; it binds to the nicotinic receptors, thereby preventing nicotine binding. This partial agonist activity induces receptor stimulation and reduces withdrawal symptoms during cessation. Varenicline blocks the dopaminergic stimulation responsible for the reinforcement and reward associated with smoking [59]. This action reduces the craving for cigarettes. The effectiveness of varenicline in smoking cessation was demonstrated in 6 clinical trials. Five of the 6 studies were randomized, controlled, clinical trials in which varenicline was shown to be superior to the placebo in helping people quit smoking. In 2 of the 5 placebocontrolled studies, varenicline-treated patients were more successful in giving up smoking than patients treated with bupropion [60-62]. 
Table 2. Pharmacologic product guide: FDA-approved medications for smoking cessation

\begin{tabular}{|c|c|c|c|c|}
\hline \multicolumn{5}{|l|}{ NRT formulations } \\
\hline gum & lozenge & transdermal patch & nasal spray & oral inhaler \\
\hline $\begin{array}{l}\text { Product } \\
\text { Nicorette }^{1} \text {, generic } \\
\text { OTC } \\
2 \text { and } 4 \mathrm{mg} \\
\text { Original, cinnamon, fruit, mint } \\
\text { (various), and orange }\end{array}$ & $\begin{array}{l}\text { Commit }{ }^{1} \text {, generic } \\
\text { OTC } \\
2 \text { and } 4 \mathrm{mg} \\
\text { Cappuccino, cherry, original } \\
\text { (light-mint), and mint }\end{array}$ & $\begin{array}{l}\text { NicoDerm CQ }{ }^{1} \text {, generic }{ }^{2} \\
\text { OTC (NicoDerm CQ, generic) } \\
\text { Rx (generic) } \\
7,14 \text {, and } 21 \mathrm{mg} \text { (24-hour release) }\end{array}$ & $\begin{array}{l}\text { Nicotrol } \mathrm{NS}^{3} \\
\mathrm{Rx} \\
\text { Metered spray } \\
0.5 \mathrm{mg} \text { nicotine in } 50 \mu \mathrm{l} \\
\text { aqueous nicotine solution }\end{array}$ & $\begin{array}{l}\text { Nicotrol inhaler }{ }^{3} \\
\mathrm{Rx} \\
10 \text {-mg cartridge delivers } 4 \mathrm{mg} \\
\text { inhaled nicotine vapor }\end{array}$ \\
\hline $\begin{array}{l}\text { Precautions } \\
\text { Recent ( } \leq 2 \text { weeks) myocardial } \\
\text { infarction } \\
\text { Serious underlying arrhythmias } \\
\text { Serious or worsening angina } \\
\text { pectoris } \\
\text { Temporomandibular joint disease } \\
\text { Pregnancy }{ }^{4} \text { and breastfeeding } \\
\text { Adolescents }(<18 \text { years) }\end{array}$ & $\begin{array}{l}\text { Recent ( } \leq 2 \text { weeks) myocardial infarction } \\
\text { Serious underlying arrhythmias } \\
\text { Serious or worsening angina pectoris } \\
\text { Pregnancy }{ }^{4} \text { and breastfeeding } \\
\text { Adolescents ( }<18 \text { years) }\end{array}$ & $\begin{array}{l}\text { Recent ( } \leq 2 \text { weeks) myocardial } \\
\text { infarction } \\
\text { Serious underlying arrhythmias } \\
\text { Serious or worsening angina } \\
\text { pectoris } \\
\text { Pregnancy }{ }^{4} \text { (Rx formulations, } \\
\text { category D) and breastfeeding } \\
\text { Adolescents ( }<18 \text { years) }\end{array}$ & $\begin{array}{l}\text { Recent ( } \leq 2 \text { weeks) } \\
\text { myocardial infarction } \\
\text { Serious underlying } \\
\text { arrhythmias } \\
\text { Serious or worsening angina } \\
\text { pectoris } \\
\text { Underlying chronic nasal } \\
\text { disorders (rhinitis, nasal } \\
\text { polyps, and sinusitis) } \\
\text { Severe reactive airway disease } \\
\text { Pregnancy }{ }^{4} \text { (category D) and } \\
\text { breastfeeding } \\
\text { Adolescents ( }<18 \text { years) }\end{array}$ & $\begin{array}{l}\text { Recent ( } \leq 2 \text { weeks) } \\
\text { myocardial infarction } \\
\text { Serious underlying } \\
\text { arrhythmias } \\
\text { Serious or worsening angina } \\
\text { pectoris } \\
\text { Bronchospastic disease } \\
\text { Pregnancy }{ }^{4} \text { (category D) and } \\
\text { breastfeeding } \\
\text { Adolescents ( }<18 \text { years) }\end{array}$ \\
\hline
\end{tabular}

\section{Dosing}

$\geq 25$ cigarettes/day: $4 \mathrm{mg}$

$<25$ cigarettes/day: $2 \mathrm{mg}$

Week 1-6: 1 piece q 1-2 h

Week 7-9: 1 piece q 2-4 h

Week 10-12: 1 piece q $4-8 \mathrm{~h}$

Maximum: 24 pieces/day

Chew each piece slowly

Park between cheek and gum when

peppery or tingling sensation

appears ( 15-30 chews)

Resume chewing when taste or

tingle fades

Repeat chew/park steps until most

of the nicotine is gone (taste or

tingle does not return; generally 30

min)

Park in different areas of mouth

No food or beverages $15 \mathrm{~min}$

before or during use

Duration: up to 12 weeks 1st cigarette $\leq 30 \mathrm{~min}$ after waking: $4 \mathrm{mg}$
1st cigarette $>30 \mathrm{~min}$ after waking: $2 \mathrm{mg}$

Week 1-6: 1 lozenge q 1-2 h

Week 7-9: 1 lozenge q 2-4 h

Week 10-12: 1 lozenge q 4-8 h

Maximum: 20 lozenges/day Allow to dissolve slowly (20-30 min)

Nicotine release may cause a warm, tingling sensation

Do not chew or swallow

Occasionally rotate to different areas of the mouth

No food or beverages $15 \mathrm{~min}$ before or

during use

Duration: up to 12 weeks
$>10$ cigarettes/day

$21 \mathrm{mg} /$ day $\times 4$ weeks (generic)

$21 \mathrm{mg} /$ day $\times 6$ weeks (NicoDerm

CQ)

$14 \mathrm{mg} /$ day $\times 2$ weeks

$7 \mathrm{mg} /$ day $\times 2$ weeks

$\leq 10$ cigarettes/day

$14 \mathrm{mg} /$ day $\times 6$ weeks

$7 \mathrm{mg} /$ day $\times 2$ weeks

May wear patch for $16 \mathrm{~h}$ if patient experiences sleep disturbances (remove at bedtime)

Duration: 8-10 weeks
1-2 doses/h

(8-40 doses/day)

One dose $=2$ sprays $(1$ in each nostril); each spray delivers $0.5 \mathrm{mg}$ of nicotine to the nasal mucosa

Maximum :

5 doses/h

40 doses/day

For best results, initially use

at least 8 doses/day

Patients should not sniff,

swallow, or inhale through

the nose as the spray is being

administered

Duration: 3-6 months
6-16 cartridges/day Individualize dosing; initially use 1 cartridge $\mathrm{q} 1-2 \mathrm{~h}$

Best effects with continuous puffing for $20 \mathrm{~min}$ Initially use at least 6 cartridges/day

Nicotine in cartridge is depleted after $20 \mathrm{~min}$ of active puffing

Patient should inhale into

back of throat or puff in short breaths

Do NOT inhale into the lungs

(like a cigarette) but 'puff' as

if lighting a pipe

Open cartridge retains

potency for $24 \mathrm{~h}$

Duration: 3-6 months

\section{Adverse effects}

Mouth/jaw soreness

Hiccups

Dyspepsia

Hypersalivation

Heartburn

chewing technique

Lightheadedness

Nausea/vomiting

Throat and mouth irritation

\section{Advantages}

Might satisfy oral cravings

Might delay weight gain

Patients can titrate therapy to

manage withdrawal symptoms

Variety of flavors are available

Nausea
Hiccups
Cough
Heartburn
Headache
Flatulence
Insomnia

Insomnia
Might satisfy oral cravings

Might delay weight gain

Easy to use and conceal

Patients can titrate therapy to manage

withdrawal symptoms

Variety of flavors are available
Local skin reactions (erythema,

pruritus, and burning)

Headache

Sleep disturbances (insomnia and abnormal/vivid dreams);

associated with nocturnal nicotine absorption
Nasal and/or throat irritation (hot, peppery, or burning sensation)

Rhinitis

Tearing

Sneezing

Cough

Headache
Mouth and/or throat

irritation

Cough

Headache

Rhinitis

Dyspepsia

Hiccups
Provides consistent nicotine levels over $24 \mathrm{~h}$

Easy to use and conceal

Once daily dosing is associated

with fewer compliance problems
Patients can titrate therapy to rapidly manage withdrawal symptoms
Patients can titrate therapy to manage withdrawal symptoms

Mimics hand-to-mouth ritual of smoking (could also be perceived as a disadvantage) 
Zyban
Rx

150-mg RS tablet
Chantix ${ }^{3}$

$\mathrm{Rx}$

0.5 - and 1-mg tablets
Concomitant therapy with medications or medical conditions known to lower the seizure threshold

Severe hepatic cirrhosis

Pregnancy ${ }^{4}$ (category C) and breastfeeding

Adolescents $(<18$ years $)$

Warning

BLACK-BOX WARNING for neuropsychiatric symptoms

Contraindications

Seizure disorder

Concomitant bupropion (e.g. Wellbutrin) therapy

Current or prior diagnosis of bulimia or anorexia nervosa

Simultaneous abrupt discontinuation of alcohol or sedatives/benzodiazepines

MAO inhibitor therapy in previous 14 days
$150 \mathrm{mg}$ p.o. $\mathrm{q} A M \times 3$ days, then

$150 \mathrm{mg}$ p.o. b.i.d.

Do not exceed $300 \mathrm{mg} / \mathrm{day}$

Patients should begin therapy 1-2 weeks prior to quitting date

Allow at least $8 \mathrm{~h}$ between doses

Avoid bedtime dosing to minimize insomnia

Dose tapering is not necessary

Can be used safely with NRT

Duration: 7-12 weeks, with maintenance up to 6 months in selected patients
Severe renal impairment (dosage adjustment is necessary)

Pregnancy ${ }^{4}$ (category C) and breastfeeding

Adolescents $(<18$ years $)$

Warnings

BLACK-BOX WARNING for neuropsychiatric symptoms ${ }^{5}$ Safety and efficacy have not been established in patients with serious psychiatric illness
Days 1-3: $0.5 \mathrm{mg}$ p.o. q AM

Days 4-7: $0.5 \mathrm{mg}$ p.o. b.i.d.

Weeks 2-12: $1 \mathrm{mg}$ p.o. b.i.d.

Patients should begin therapy 1 week prior to quitting date Take dose after eating, with a full glass of water Dose tapering is not necessary

Nausea and insomnia are side effects that are usually temporary Duration: 12 weeks; an additional 12-week course may be used in selected patients
Insomnia

Dry mouth

Nervousness/difficulty concentrating

Rash

Constipation

Seizures [risk is $1 / 1,000(0.1 \%)$ ]
Nausea

Sleep disturbances (insomnia and abnormal/vivid dreams)

Constipation

Flatulence

Vomiting

Neuropsychiatric symptoms (see 'Precautions', above)
Easy to use; oral formulation might be associated

with fewer compliance problems

Might delay weight gain

Can be used with NRT

Might be beneficial in patients with depression
Easy to use; oral formulation might be associated with fewer compliance problems

Offers a new mechanism of action for patients who have failed other agents 
Table 2 (continued)

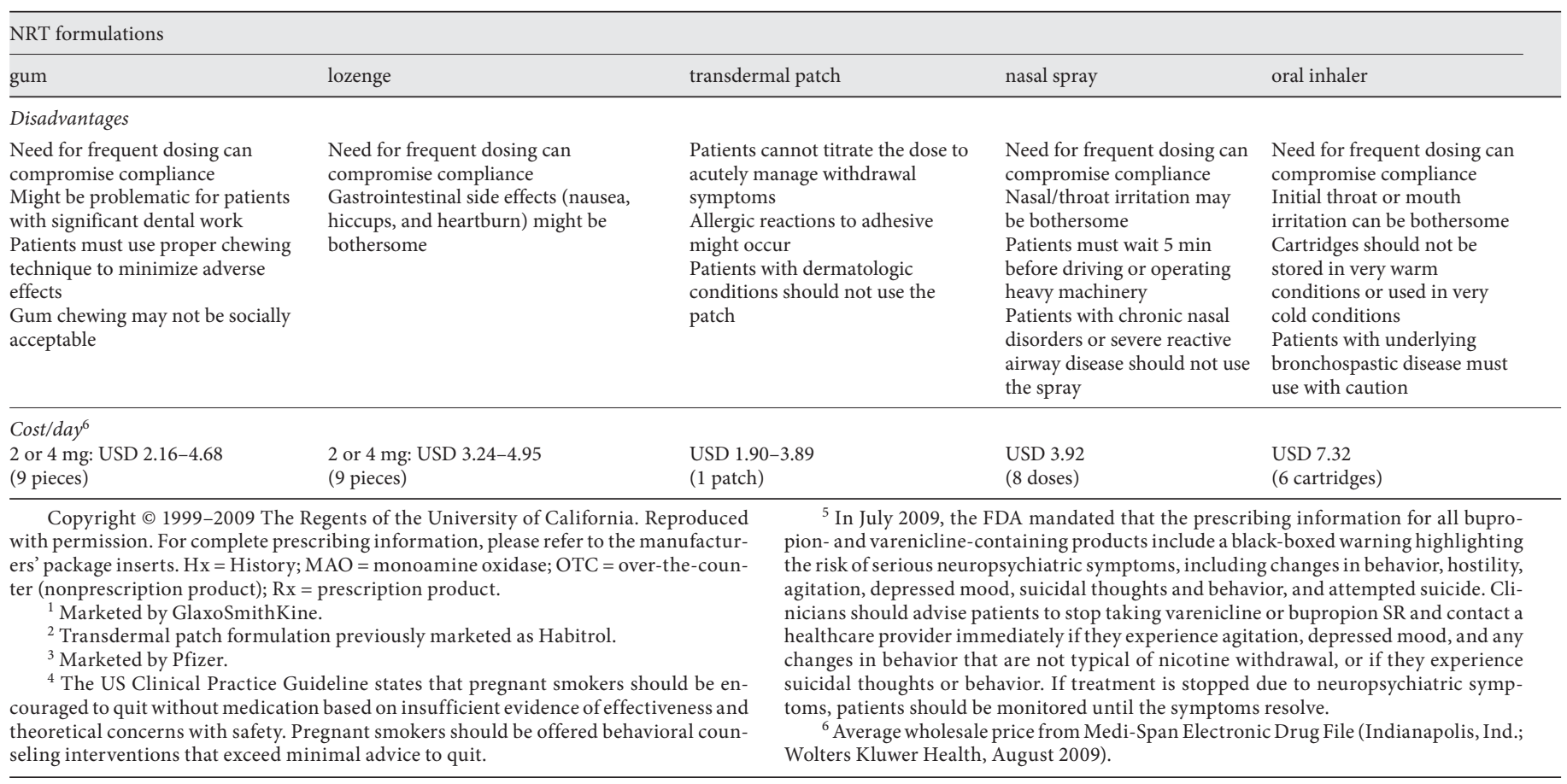

There have been case reports of neuropsychiatric symptoms (behavior changes, agitation, depressed mood, and suicidal ideation or behavior) and reports of worsening of preexisting psychiatric illness. These reports are rare in comparison to the total number of patients using the medication [63]. Clinicians need to closely monitor for neuropsychiatric symptoms while patients are using varenicline and bupropion as smoking cessation aids [64].

- Combination Pharmacotherapy. Data from randomized, controlled trials suggest that certain combinations of first-line cessation medications are efficacious in promoting long-term abstinence. As such, the 2008 Clinical Practice Guideline considers the following regimens to be appropriate first-line therapy in patients attempting to quit smoking [54]:

- Combination NRT. Combination NRT according to $\mathrm{Rx}$ for Change [65] involves the use of a long-acting formulation (patch) in combination with a shortacting formulation (gum, lozenge, inhaler, or nasal spray). The long-acting formulation, which delivers relatively constant levels of the drug, is used to prevent the onset of severe withdrawal symptoms, and the short-acting formulation, which delivers nicotine at a faster rate, is used as needed to control withdrawal symptoms that may occur during po- tential relapse situations (e.g. after meals, when under stress, or when around other smokers). A recent meta-analysis found that the nicotine patch in combination with a short-acting NRT formulation (gum, inhaler, or nasal spray) was significantly more effective than single-agent NRT. The odds of long-term ( $\geq 6$ months) cessation were 1.4 with combination therapy compared to monotherapy (95\% CI 1.1-1.6) [65, 66].

- NRT and Bupropion SR. Combination therapy with bupropion SR and NRT has been evaluated in 3 long-term controlled trials. Patients receiving combination therapy in standard dosages were significantly more likely to quit than were patients randomized to the nicotine patch alone. The odds of long term ( $\geq 6$ months) abstinence were 1.3 with the combination therapy compared to the nicotine patch monotherapy (95\% CI 1.0-1.8) [54].

\section{Tobacco Dependence Treatment for Cancer Patients}

Patients with cancer may have higher levels of nicotine dependence, higher levels of co-morbidity, or more difficulty quitting, as well as poorer health and physical func- 
Seizure risk is increased

Several contraindications and precautions

preclude use in some patients

(see 'Precautions', above)
May induce nausea in up to one third of patients

Postmarketing surveillance data indicate potential for neuropsychiatric symptoms

(see 'Precautions', above)

(2 tablets) (2 tablets)

tioning, and more stress and emotional distress, suggesting the need for more intense or tailored programs [67, 68]. Given the impact of smoking on treatment (surgery, radiation, and chemotherapy), a patient's smoking status should be considered as part of the treatment decisions. Systematic advice received from multiple providers is more effective than advice from a single provider [54]. A stepped care approach may be useful for patients experiencing difficulty with quitting [52]. Schnoll et al. [69] highlighted the need for motivational smoking cessation interventions for cancer patients. They investigated the difference between cancer patients who enroll in smoking cessation programs and those that do not. Decliners were significantly more likely to have head and neck cancer (vs. lung cancer) and report a lower readiness to quit smoking. There are few randomized clinical trials investigating tobacco dependence treatment for lung cancer patients [70].

\section{Tobacco Dependence Treatment for Highly Dependent Smokers}

Tobacco dependence is a chronic disease and relapse is intrinsic to this disease. Lung cancer patients who smoke are, more often than not, highly dependent smok- ers. For the highly dependent smoker, tailored intensive interventions that combine behavioral interventions with pharmacologic cessation aides may be helpful [5]. Combination pharmacotherapy has also been found to be effective with highly dependent smokers [71]. Intensive interventions, however, may not be appropriate for all lung cancer patients, so other innovative interventions need to be considered. The use of telephone counseling has been shown to be effective among the general population and is now available in every state throughout the US (1-800-Quit-Now) [72]. Evidence has shown that proactive counseling helps motivated smokers stay abstinent and that 3 or more calls increase the odds of quitting compared with standard self-help or brief health care provider advice [73].

Other literature that can inform tailored cessation counseling for lung cancer patients includes studies that have targeted older smokers. The mean age of lung cancer patients is 70 years [74]. Hall et al. [58] purport that treatment for older smokers needs to conceptualize tobacco dependence as a chronic disease; most smokers have multiple quitting attempts and relapse is the norm $[75,76]$. Hall et al. achieved abstinence rates with older smokers of more than 55\% at 24, 52, 64, and 104 weeks using bupropion and extended cognitive behavioral treatment. 


\section{Treatment Factors Specific to Treating Smokers with}

\section{Lung Cancer}

Only 3 smoking cessation intervention studies have been conducted with diagnosed lung cancer patients [45, 77, 78]. In 1997, a smoking cessation intervention was evaluated among patients with lung cancer during hospitalization. Upon admission, $87 \%$ of the subjects expressed intent to quit smoking in the next month. The intervention included only 15 subjects and consisted of 3 daily 20 - to 30 -min visits and 5 weekly follow-up phone calls. At 6 weeks postintervention, 14 (93\%) subjects reported making at least 1 quitting attempt and $40 \%$ were confirmed abstinent. The finding suggested that a more intensive intervention can succeed and would be of interest to lung cancer patients [55]. Browning et al. [77] evaluated the effectiveness of a smoking cessation intervention that included face-to-face and phone follow-up behavioral interventions with 14 patients with lung cancer. The number of subjects using NRT was not noted and only 3 subjects used bupropion. Cox et al. [45] found that nicotine dependence treatment is effective for patients with a lung cancer diagnosis and that the majority of lung cancer patients were motivated to quit smoking. The 6-month tobacco abstinence rate was $22 \%$ for the lung cancer patients compared with $14 \%$ for the control patients $(\mathrm{p}=$ 0.024). The intervention involved a brief consultation with a cessation counselor and a treatment plan individualized to the patient's needs. Data on the type of recommended interventions and whether patients adhered to these recommendations were not entered into the database. None of the interventions studied in the literature met the US Public Health Service Guidelines recommendation for a combination of both behavioral and pharmacologic treatment [54].

There are several additional features based on the 2008 guidelines for smoking cessation [54] to consider when treating tobacco dependence in patients with lung cancer.

- Motivation. Improving one's health may not be the most effective motivational factor; however, providing information about the short-term and long-term benefits of smoking cessation during lung cancer treatment is essential. Evidence suggests that the majority of lung cancer patients are motivated to stop smoking [45]. Although a diagnosis of lung cancer is assumed to be a strong motivator, lung cancer patients who smoke are at various stages of readiness to quit. For the lung cancer patient the time of diagnosis provides a window of opportunity where receptivity to a smoking cessation attempt may be increased. However, if this opportunity is not realized at the time of diagno- sis the health care provider needs to continue to ask and assess for readiness throughout the course of treatment. Previous attempts at smoking cessation can be framed as opportunities to discover effective strategies for successful cessation. Tone and manner should convey a concern for the patient's well-being as well as a commitment to help him or her quit, when the patient is ready. The message is: 'It's important that you quit as soon as possible, and I can help you.' For those patients willing to quit, extended treatment has been found to be the most effective with older smokers and is essential for lung cancer patients; smoking cessation should be an integral part of the entire course of lung cancer treatment [58].

- Stigma and Self-Blame. Anecdotal evidence suggests that stigma is an important factor in the care of lung cancer patients [79]. Whether they smoked or not, lung cancer patients reported stigmatization from clinicians, as well as family members and friends, because the disease is strongly associated with smoking [79]. Smokers have become a marginalized part of society [80]. Current and former smokers have identified several factors that contribute to perceptions of LCS including: perceptions of smoking as a choice, not an addiction; discrimination perpetrated against smokers through no-smoking policies, and perceptions that smokers are less educated [80]. Recently, with the development of the lung cancer stigma scale, there is empirical evidence that lung cancer patients experience significant levels of perceived stigma whether or not they are current or past smokers. Stigma had a strong significant correlation with increased depression and diminished QOL [Cataldo et al., unpubl. data]. Education about coping strategies to deal with self-blame and stigma needs to be incorporated into the smoking cessation intervention.

- Mood Management. As a result of a lung cancer diagnosis, patients often experience increased psychological distress, increased feelings of burden, stress, and stigmatization [81-84]. Lung cancer patients experience more psychological distress than other cancer patients, making mood management an essential aspect of treatment. It is important to evaluate and treat the patient for mood disorders and assist patients in the identification of effective coping strategies. Coping strategies are an essential part of smoking cessation for lung cancer patients.

- Smoke-Free Homes. Considerable evidence suggests that having a smoke-free home may be associated with increased successful quitting [85-87]. Smokers who 
adopt a smoke-free home are almost 5 times more likely to quit for $\geq 90$ days [87]. It is important to explain the impact of second-hand smoke on the health of pets and others and to encourage a contract for a smokefree environment to be signed by the patient and their significant circle.

- Social Support. Little perceived social support has been found to predict smoking relapse [88-90]. It is important to include in the intervention management a current support network and to identify those supporting cessation and smoking. Bottoroff et al. [81] investigated continued family smoking after lung cancer diagnosis and found that clinicians need to focus on collective behavior in the family setting to understand processes that influence health behavior changes. It is important to assist patients in finding ways to elicit positive support and handle negative support. Research suggests that partner involvement in smoking cessation may encourage long-term abstinence. Park et al. [91] found that interventions to enhance partner support showed the most promise when implemented with live-in, married, and equivalent-to-married partners. They concluded that such interventions should focus on enhancing supportive behaviors, while minimizing behaviors critical of smoking. A strong predictor of relapse is having another smoker in the home [87]. Lung cancer patients often live with a smoker; treating a dyad or more than 1 smoker in a home may increase the chances of smoking abstinence success.

\section{Conclusion}

The lung cancer experience is unique in many ways (with issues of self-blame and stigma, anticipated short survival time, and increased symptom burden and distress), the lung cancer patient who smokes is highly dependent on tobacco while faced with an urgent life crisis; research is needed to develop effective and tailored smoking cessation interventions. Given the prevalence of lung cancer patients who smoke and the significant benefits of smoking cessation, cancer care providers need to offer full support and tobacco dependence treatment that is tailored to patients' specific needs. Intensive and extended tobacco cessation programs, including counseling with behavioral therapy and the use of nicotine replacement and combined pharmacology with extended followup, are highly efficacious, cost-effective, and a critical component of quality lung cancer care.

\section{Acknowledgements}

This research was supported by California Tobacco-Related Disease Research Program (TRDRP) grants 16RT-0149 and 17RT0077, National Institute of Drug Addiction grant K23-DA018691, and National Institute of Nursing Research grant NR011934-01.

\section{References}

1 US Cancer Statistics Working Group: United States Cancer Statistics: 2004 Incidence and Mortality. Atlanta, US Department of Health and Human Services, Centers for Disease Control and Prevention and National Cancer Institute, 2007.

2 American Cancer Society: Cancer Facts and Figures - 2007. Atlanta, American Cancer Society, 2007.

3 Cox LS, Africano NL, Tercyak KP, Taylor KL: Nicotine dependence treatment for patients with cancer. Cancer 2003;98:632-644.

-4 Centers for Disease Control and Prevention (CDC): State-specific prevalence of current cigarette smoking among adults and secondhand smoke rules and policies in homes and workplaces - United States 2005. MMWR Morb Mortal Wkly Rep 2006;55:1148-1151.

5 Cooley ME, Sipples RL, Murphy M, Sarna L: Smoking cessation and lung cancer: oncolo- gy nurses can make a difference. Semin Oncol Nurs 2008;24:16-26.

-6 Dresler CM: Is it more important to quit smoking than which chemotherapy is used? Lung Cancer 2003;39:119-124.

7 Fox JL, Rosenzweig KE, Ostroff JS: The effect of smoking status on survival following radiation therapy for non-small cell lung cancer. Lung Cancer 2004;44:287-293.

-8 Sanderson C, Africano N, Tercyak K: Nicotine dependence treatment for patients with cancer. Cancer 2003;98:632-634.

-9 Sardari Nia P, Weyler J, Colpaert C, Vermeulen P, Marck EV, Schil PV: Prognostic value of smoking status in operated nonsmall cell lung cancer. Lung Cancer 2005; 47:351-359.

10 Parsons A, Daley A, Begh R, Aveyard P: Influence of smoking cessation after diagnosis of early stage lung cancer on prognosis: sys- tematic review of observational studies with meta-analysis. BMJ 2010;340:b5569.

11 Cataldo JK: Smoking and aging: breaking through the barriers. J Gerontol Nurs 2007; 33:32-41.

12 Ries LAG, Melbert D, Krapcho M, et al: SEER Cancer Statistics Review, 1975-2004, National Cancer Institute, Bethesda, MD, based on November 2006 SEER data submission, posted to the SEER Web site, 2007.

13 Molina JR, Yang P, Cassivi SD, Schild SE, Adjei AA: Non-small cell lung cancer: epidemiology, risk factors, treatment, and survivorship. Mayo Clin Proc 2008;83:584-594.

14 Croghan IT, Schroeder DR, Hays JT, Eberman KM, Patten CA, Berg EJ, et al: Nicotine dependence treatment: perceived health status improvement with 1-year continuous smoking abstinence. Eur J Public Health 2005; 15:251-255. 
15 Slatore CG, Au DH, Hollingworth W: Costeffectiveness of a smoking cessation program implemented at the time of surgery for lung cancer. J Thorac Oncol 2009;4:499-504.

16 de Moor J, Elder K, Emmons KM: Smoking prevention and cessation interventions for cancer survivors. Semin Oncol Nurs 2008; 24:180-192.

17 US Department of Health and Human Services: Clinical Practice Guideline: Treating Tobacco Use and Dependence. A Report from the Surgeon General. US Department of Health and Human Services Public Health Services, Office. Washington, 2000.

- 18 Sarna L, Padilla G, Holmes C, Tashkin D, Brecht ML, Evangelista L: Quality of life of long-term survivors of non-small-cell lung cancer. J Clin Oncol 2002;20:2920-2929.

-19 Stewart A, King A, Killen J: Does smoking cessation improve health-related quality of life? Ann Behav Med 1995;17:331-338.

20 Garces YI, Yang P, Parkinson J, Zhao X, Wampfler JA, Ebbert JO, et al: The relationship between cigarette smoking and quality of life after lung cancer diagnosis. Chest 2004; 126:1733-1741.

-21 Baser S, Shannon V, Eapen G, Jimenez C, Onn A, Lin E, et al: Smoking cessation after diagnosis of lung cancer is associated with a beneficial effect on performance status. Chest 2006;130:1784-1790.

22 Cooley ME: Symptoms in adults with lung cancer: a systematic research review. J Pain Symptom Manage 2000;19:137-153.

-23 Huang J, Behrens C, Wistuba I, Gazdar AF, Jagirdar J: Molecular analysis of synchronous and metachronous tumors of the lung: impact on management and prognosis. Ann Diagn Pathol 2001;5:321-329.

-24 Trousse D, Barlesi F, Loundou A, Tasei AM, Doddoli C, Giudicelli R, et al: Synchronous multiple primary lung cancer: an increasing clinical occurrence requiring multidisciplinary management. J Thorac Cardiovasc Surg 2007;133:1193-1200.

-25 Tucker MA: Second primary cancers related to smoking and treatment of small-cell lung cancer. Lung Cancer Working Cadre. J Natl Cancer Inst 1997;89:1782-1788.

-26 Richardson GE, Tucker MA, Venzon DJ, Linnoila RI, Phelps R, Phares JC, et al: Smoking cessation after successful treatment of small-cell lung cancer is associated with fewer smoking-related second primary cancers. Ann Intern Med 1993;119:383-390.

-27 Do KA, Johnson MM, Doherty DA, Lee JJ, Wu XF, Dong Q, et al: Second primary tumors in patients with upper aerodigestive tract cancers: joint effects of smoking and alcohol (United States). Cancer Causes Control 2003; 14:131-138.

-28 Rice D, Kim HW, Sabichi A, Lippman S, Lee JJ, Williams B, et al: The risk of second primary tumors after resection of stage I nonsmall cell lung cancer. Ann Thorac Surg 2003;76:1001-1008.
29 Johnson BE: Second lung cancers in patients after treatment for an initial lung cancer. J Natl Cancer Inst 1998;90:1335-1345.

30 Hoffmann D, Hoffmann I: The changing cigarette, 1950-1995. J Toxicol Environ Health 1997;50:307-364.

31 Zevin S, Benowitz NL: Drug interactions with tobacco smoking: an update. Clin Pharmacokinet 1999;36:425-438.

32 Benowitz NL: The role of nicotine in smoking-related cardiovascular disease. Prev Med 1997;26:412-417.

33 Xu J, Huang H, Pan C, Zhang B, Liu X, Zhang L: Nicotine inhibits apoptosis induced by cisplatin in human oral cancer cells. Int J Oral Maxillofac Surg 2007;36:739-744.

-34 Dasgupta P, Rizwani W, Pillai S, Kinkade R, Kovacs M, Rastogi S, et al: Nicotine induces cell proliferation, invasion and epithelialmesenchymal transition in a variety of human cancer cell lines. Int J Cancer 2009;124: 36-45.

35 Gritz ER, Vidrine DJ, Lazev AB: Smoking cessation in cancer patients: never too late to quit; in Given B, Given CW, Champion V Kozachik S, Devoss D (eds): Evidence-Based Cancer Care and Prevention: Behavioral Interventions. New York, Springer, 2003, pp 107-140.

-36 Fujisawa T, Iizasa T, Saitoh Y, Sekine Y, Motohashi S, Yasukawa T, et al: Smoking before surgery predicts poor long-term survival in patients with stage I non-small-cell lung carcinomas. J Clin Oncol 1999;17:2086-2091.

37 Lippman SM, Lee JJ, Karp DD, Vokes EE, Benner SE, Goodman GE, et al: Randomized phase III intergroup trial of isotretinoin to prevent second primary tumors in stage I non-small-cell lung cancer. J Natl Cancer Inst 2001;93:605-618.

38 Ebbert JO, Yang P, Vachon CM, Vierkant RA, Cerhan JR, Folsom AR, et al: Lung cancer risk reduction after smoking cessation: observations from a prospective cohort of women. J Clin Oncol 2003;21:921-926.

39 Videtic GM, Stitt LW, Dar AR, Kocha WI, Tomiak AT, Truong PT, et al: Continued cigarette smoking by patients receiving concurrent chemoradiotherapy for limited-stage small-cell lung cancer is associated with decreased survival. J Clin Oncol 2003;21:15441549.

40 Tammemagi CM, Neslund-Dudas C, Simoff M, Kvale P: Smoking and lung cancer survival: the role of comorbidity and treatment. Chest 2004;125:27-37.

41 Moller A, Villebro N, Pedersen T, et al: Effect of preoperative smoking intervention on postoperative complications: a randomised clinical trial. Lancet 2002;359:114-117.

-42 Yildizeli B, Fadel E, Mussot S, Fabre D, Chataigner O, Dartevelle PG: Morbidity, mortality, and long-term survival after sleeve lobectomy for non-small cell lung cancer. Eur Cardiothorac Surg 2007;31:95-102.
43 Suzuki M, Otsuji M, Baba M, Saitoh Y, Iizasa T, Shibuya K, et al: Bronchopleural fistula after lung cancer surgery: multivariate analysis of risk factors. J Cardiovas Surg (Torino) 2002;43:263-267.

-44 Barrera R, Shi W, Amar D, Thaler HT, Gabovich N, Bains MS, et al: Smoking and timing of cessation: impact on pulmonary complications after thoracotomy. Chest 2005;127: 1977-1983.

$\checkmark 4$ Cox LS, Patten CA, Ebbert JO, Drews AA, Croghan GA, Clark MM, et al: Tobacco use outcomes among patients with lung cancer treated for nicotine dependence. J Clin Oncol 2002;20:3461-3469.

46 van der Bol JM, Mathijssen RHJ, Loos WJ, Friberg LE, van Schaik RH, de Jonge MJ, et al: Cigarette smoking and irinotecan treatment: pharmacokinetic interaction and effects on neutropenia. J Clin Oncol 2007;25: 2719-2726.

47 Mohan A, Singh P, Kumar S, Zoltan S, Mohan C, Pathak AK, et al: Effect of change in symptoms, respiratory status, nutritional profile and quality of life on response to treatment for advanced non-small cell lung cancer. Asian Pac J Cancer Prev 2008;9:557562.

$\checkmark 48$ Shepherd FA, Rodrigues Pereira J, Ciuleanu T, Tan EH, Hirsh V, Thongprasert S, et al: Erlotinib in previously treated non-smallcell lung cancer. N Engl J Med 2005;353:123132 .

49 Hughes AN, O’Brien M, Petty W, Chick J, Rankin E, Woll, et al: Overcoming CYP1A1/1A2 mediated induction of metabolism by escalating erlotinib dose in current smokers. J Clin Oncol 2009;27:1220-1226.

50 Monson J, Stark P, Reilly J: Clinical radiation pneumonitis and radiographic changes after thoracic radiation therapy for lung carcinoma. Cancer 1998;82:842-850.

-51 Sarihan S, Ercan I, Saran A, Çetintas SK, Akalin H, Engin K: Evaluation of infections in non-small cell lung cancer patients treated with radiotherapy. Cancer Detect Prev 2005; 29:181-188.

52 Gritz ER, Fingeret MC, Vidrine DJ, Lazev AB, Mehta NV, Reece GP: Successes and failures of the teachable moment: smoking cessation in cancer patients. Cancer 2006;106: 17-27.

53 Myrdal G, Valtysdottir S, Lambe M, Stahle E: Quality of life following lung cancer surgery. Thorax 2003;58:194-197.

54 Fiore M, Jaén C, Baker TB: Treating Tobacco Use and Dependence: 2008 Update. Clinical Practice Guideline. Rockville, US Department of Health and Human Services. Public Health Service, 2008.

55 Henningfield JE, Fant RV, Buchhalter AR, Stitzer ML: Pharmacotherapy for nicotine dependence. CA Cancer J Clinic 2005;55: 281-299. 
56 Ziedonis DM, Wyatt S, George T (eds): Current Issues in Nicotine Dependence Treatment. Washington, American Psychiatric Publishing, 1998.

-57 Cox L, Patten C, Niaura R, Decker P, Rigotti $\mathrm{N}$, Sachs D, et al: Efficacy of bupropion for relapse prevention in smokers with and without a past history of major depression. J Gen Intern Med 2004;19:828-834.

- 58 Hall SM, Humfleet GL, Munoz RF, Reus VI, Robbins JA, Prochaska JJ: Extended treatment of older cigarette smokers. Addiction 2009;104:1043-1052.

59 Foulds J: The neurobiologcial basis for partial agonist treatment of nicotine dependence: varenicline. Int J Clin Pract 2006;60: 571-576.

-60 Gonzales D, Rennard S, Nides MA, Oncken C, Azoulay S, Billing C: Varenicline, an alpha4beta2 nicotinic acetylcholine receptor partial agonist, vs. sustained-release bupropion and placebo for smoking cessation: a randomized controlled trial. JAMA 2006; 296:47-55.

-61 Jorenby D, Hays J, Rigotti N, Azoulay S, Watsky E, Williams K: Efficacy of varenicline, an alpha4beta2 nicotinic acetylcholine receptor partial agonist, vs. placebo or sustained-release bupropion for smoking cessation: a randomized controlled trial. JAMA 2006;296:56-63.

-62 Tonstad S, Tønnesen P, Hajek P, Williams K, Billing C, Reeves K, et al: Effect of maintenance therapy with varenicline on smoking cessation: a randomized controlled trial. JAMA 2006;296:2555-2556.

63 Chantix package insert. New York, Pfizer, 2008.

64 FDA: Varenicline and bupropion. Drug Safety Newsletter 2009:2/1.

65 University of California: Rx for Change. 2010. http://rxforchange.ucsf.edu/ (accessed March 6, 2010).

66 Stead LF, Perera R, Bullen C, Mant D, Lancaster T: Nicotine replacement therapy for smoking cessation. Cochrane Database Syst Rev (online). 2008.

- 67 Schnoll RA, Calvin J, Malstrom M, Rothman $\mathrm{RL}$, Wang H, Babb J, et al: Longitudinal predictors of continued tobacco use among patients diagnosed with cancer. Ann Behav Med 2003;25:214-221.

-68 Stanislaw AE, Wewers ME: A smoking cessation intervention with hospitalized surgical cancer patients: a pilot study. Cancer Nurs 1994;17:81-86.
69 Schnoll RA, Rothman RL, Lerman C, Miller SM, Newman H, Movsas B, et al: Comparing cancer patients who enroll in a smoking cessation program at a comprehensive cancer center with those who decline enrollment. Head Neck 2004;26:278-286.

70 Schnoll RA, Rothman RL, Wielt DB, Pedri $\mathrm{H}$, Wang $\mathrm{H}, \mathrm{Babb}$ J, et al: A randomized pilot study of cognitive-behavioral therapy versus basic health education for smoking cessation among cancer patients. Ann Behav Med 2005;30:1-11.

71 Cooney NL, Cooney JL, Perry BL, Carbone M, Cohen EH, Steinberg HR, et al: Smoking cessation during alcohol treatment: a randomized trial of combination nicotine patch plus nicotine gum. Addiction 2009;104: 1588-1596.

72 Cooley ME, Sarna L, Kotlerman J, Lukanich JM, Jaklitsch M, Bueno R: Smoking cessation is challenging even after lung cancer surgery. J Clin Oncol 2007;25(No. 18S):abstract 19507.

73 Stead LF, Perera R, Lancaster T: Telephone counselling for smoking cessation. Cochrane Database Syst Rev 2003;3:CD002850.

74 Hayat M, Howlader N, Reichman M, Edwards B: Cancer statistics, trends, and multiple primary cancer analyses from the Surveillance, Epidemiology, and End Results (SEER) Program. Oncologist 2007;12:20-37.

75 Garvey A, Bliss R, Hitchcock J, Heinhold J, Rosner B: Predictors of smoking relapse among self quitters: a report from the Normative Aging Study. Addict Behav 1992;17: 367-377.

76 Lichtenstein E, Weiss S, Hitchcock J, Leveton L, O'Connell K, Prochaska J: Patterns of smoking relapse. Health Psychol 1986;5 (suppl):29-40.

$\checkmark 77$ Browning KK, Ahijevych KL, Ross P Jr, Wewers ME: Implementing the Agency for Health Care Policy and Research's Smoking Cessation Guideline in a lung cancer surgery clinic. Oncol Nurs Forum 2000;27:12481254.

78 Wewers ME, Jenkins L, Mignery T: A nursemanaged smoking cessation intervention during diagnostic testing for lung cancer. Oncol Nurs Forum 1997;24:1419-1422.

79 Chapple A, Ziebland S, McPherson A: Stigma, shame, and blame experienced by patients with lung cancer: qualitative study. BMJ 2004;328:1470.

80 Stuber J, Galea S, Link BG: Smoking and the emergence of a stigmatized social status. Soc Sci Med 2008;67:420-430.
81 Bottorff JL, Robinson CA, Sullivan KM, Smith ML: Continued family smoking after lung cancer diagnosis: the patient's perspective. Oncol Nurs Forum 2009;36:E126-E132.

82 Henoch I, Bergman B, Gustafsson M, Gaston-Johansson F, Danielson E: The impact of symptoms, coping capacity, and social support on quality of life experience over time in patients with lung cancer. J Pain Symptom Manage 2007;34:370-379.

83 McBride CM, Pollak KI, Garst J, Keefe F, Lyna P, Fish L, et al: Distress and motivation for smoking cessation among lung cancer patients' relatives who smoke. J Cancer Educ 2003;18:150-156

$>84$ Sarna L, Brown JK, Cooley ME, Williams RD, Chernecky C, Padilla G, et al: Quality of life and meaning of illness of women with lung cancer. Oncol Nurs Forum 2005;32:E9E19.

85 Messer K, Mills AL, White MM, Pierce JP: The effect of smoke-free homes on smoking behavior in the US. Am J Prev Med 2008;35: 210-216.

86 Gilpin EA, Pierce JP: Demographic differences in patterns in the incidence of smoking cessation: United States 1950-1990. Ann Epidemiol 2002;12:141-150.

87 Gilpin EA, White MM, Farkas AJ, Pierce JP: Home smoking restrictions: which smokers have them and how they are associated with smoking behavior. Nicotine Tob Res 1999;1: 153-162.

88 Gulliver SB, Hughes JR, Solomon LJ, Dey AN: An investigation of self-efficacy, partner support and daily stresses as predictors of relapse to smoking in self-quitters. Addiction 1995;90:767-772.

89 Piasecki TM, Baker TB: Any further progress in smoking cessation treatment? Nicotine Tob Res 2001;3:311-323.

$>90$ Hanson BS, Isacsson SO, Janzon L, Lindell SE: Social support and quitting smoking for good: is there an association? Results from the population study, 'Men born in 1914,' Malmö, Sweden. Addict Behav 1990;15:221233.

91 Park EW, Tudiver F, Schultz JK, Campbell T: Does enhancing partner support and interaction improve smoking cessation? A metaanalysis. Ann Fam Med 2004;2:170-174.

92 Prochaska J, DiClemente C, Velicer W, Rossi $\mathrm{J}$ : Stages and processes of self-change of smoking: toward an integrative model of change. J Consult Clin Psychol 1983;51:390395. 